\title{
The practical considerations of dose constraints in diagnostic medical departments using ionizing radiation
}

\author{
H. Piwowarska-Bilska ${ }^{1}$, M. Nowak ${ }^{2}$, M.H. Listewnik ${ }^{1}$, P. Zorga ${ }^{1}$ and B. Birkenfeld ${ }^{1}$ \\ 1 Department of Nuclear Medicine, Pomeranian Medical University, Szczecin, Poland. \\ 2 Department of Diagnostic Imaging and Interventional Radiology, Pomeranian Medical University, Szczecin, Poland.
}

Received 19 March 2013 - Accepted 22 May 2013

\begin{abstract}
The term "dose constraint" has been used in radiological protection since 1990. Its practical application has varied from country to country to the present day. The authors of this paper believe that it is an underestimated tool for the purpose of radiological protection. This study aims to estimate local dose constraints for workers in conventional nuclear medicine and radiology departments, on the basis of doses received in the last 3 to 4 years by different groups of workers. The levels of exposure to employees of the nuclear medicine department correspond well to levels in other countries, but for employees belonging to the radiology department, the levels are significantly lower. Unification of the practical application of dose constraints and legislation concerning their specific values would increase the relevance and effectiveness of these operational units. This is a playing field for radiation safety officers for the determination and widespread publication of local dose constraints in their particular medical departments.
\end{abstract}

Keywords: dosimetry / dose constraints / exposure to personnel

\section{Introduction}

The term "dose constraint" was introduced to radiological protection in 1990 in the ICRP Publication 60 (1991) as a value below which all effective doses should be kept. The concept of dose constraints was brought in as law in 1996 through the EU Directive 96/29/Euratom (1996). Dose constraints should be used within the optimization of radiological protection for, inter alia, occupationally exposed persons. According to ICRP Publication 103 (2007), numerical values of dose constraints should be lower than the dose limit of $20 \mathrm{mSv}$ for occupational groups. Most European countries have introduced the term "dose constraint" into their national laws and regulations. However, there are wide variations in the translation of this concept into different languages. There is no consistency in the terminology used by the countries. Similarly, inconsistencies in approaches as to how "dose constraints" are applied can be observed. It is not known whether the dose should be applied to operational constraints (defined in relation to the tasks that the employee should perform) or to the design of the facility (specified source of radiation). In some countries, the numerical values of dose constraints are determined by the employer, whereas other dose constraints are given by the regulatory body. Due to the complexity of the issue there is a lack of methodological tools for determining dose constraints in the medical field. IAEA recommendations are general guidelines and advise on how to determine dose level constraints (IAEA, 1999).

\footnotetext{
a hanna.piwowarska@pum.edu.pl
}

Poland introduced the concept of dose constraints into the national radiation protection regulations. Thus, the Polish National Atomic Energy Agency requires a licensing request for operations that involve exposure to ionizing radiation, which includes the proposed dose limits (dose constraint) related to the operations indicated in the request. The numerical value of this dose constraint should be assessed a priori and should not be exceeded by the employees. However, permission to operate, issued by the Polish National Atomic Energy Agency, usually does not contain numerical values for dose constraints. This approach allows for verification and modification of dose levels by a radiation safety officer, when necessary.

Prospective estimation of doses may be simple for radiology or radiotherapy departments using sealed sources of radiation. Is it possible to estimate a priori dose limitation for employees of a conventional nuclear medicine department? It may be challenging. Most of the conventional nuclear medicine departments use ten different radiopharmaceuticals for numerous medical procedures, and the staff works in a rotation shift system. The safe value given in the documents as the dose constraint for employees in medical facilities using open sources of ionizing radiation in Poland is $6 \mathrm{mSv}$, due to the fact that, in Poland, an employer classifies exposed employees into the A or B categories. In accordance with Polish regulations, category B workers should not exceed the annual dose of $6 \mathrm{mSv}$. Otherwise, for conventional nuclear medicine departments, annual doses to exposed workers are significantly lower than $6 \mathrm{mSv}$ (Croft and Lefuare, 2002; Martins et al., 2007; Valuckas et al., 2007). The adoption of dose constraints which are too high would cause them to be ineffective in their role. 
Table 1. Dose data for workers occupied in the fields of a nuclear medicine department and radiology for the years 2008-2011 and 2009-2011, respectively.

\begin{tabular}{lccccc}
\hline & $\begin{array}{c}\text { Number of } \\
\text { annual dose } \\
\text { records }\end{array}$ & $\begin{array}{c}\text { Upper third } \\
\text { quartile } \\
(\mathbf{m S v})\end{array}$ & $\begin{array}{c}\text { Average } \\
\text { annual dose } \\
(\mathbf{m S v})\end{array}$ & $\begin{array}{c}\text { Dominant } \\
\text { annual dose } \\
(\mathbf{m S v})\end{array}$ & $\begin{array}{c}\text { Proposed } \\
\text { dose constraint } \\
(\mathbf{m S v})\end{array}$ \\
\hline Department of Nuclear Medicine & & & & & \\
Nurses & 12 & 2.03 & 2.21 & 0.40 & 2.50 \\
Technicians & 28 & 2.03 & 1.74 & 0.10 & \\
Medical doctors & 21 & 0.50 & 0.36 & & \\
Department of & & & & $-*$ & \\
Diagnostic Imaging & & & & 0.1 & \\
and Interventional & & & & & \\
Radiology & 7 & 0.90 & 0.68 & & 1.0 \\
Nurses & 30 & 0.10 & 0.13 & & 1.0 \\
Technicians & 29 & 0.28 & 0.29 & & 1.0 \\
Medical doctors & & & & & \\
\hline
\end{tabular}

* Value was not available due to the lack of repeated doses.

However, from a practical viewpoint, the dose constraint concept is very useful, mainly for two reasons. Generally, employees do not exceed the high annual dose limit, thus the radiation safety officer might lose arguments that encourage the strict use of radiation shielding during staff training and convince management of the need to purchase new means of radiation protection. The optimal, and most of all, real dose constraints for specific occupational groups can become an effective tool to raise the radiation protection level. How, then, should the optimal dose constraints be determined? It seems that there is no other option but to study the doses received in recent years, including the planned changes. Thus, the authors of this paper present a very simple technique to determine the dose constraint level based on the analysis of 3-4 years of annual doses received by exposed workers. Publication of such data for a dozen departments in the country could result in the introduction of numerical values of the dose constraints into national regulations.

\section{Methods}

Overall, 127 annual doses of the employees of the Department of nuclear medicine (DNM) and Department of diagnostic imaging and interventional radiology (DDIIR), registered in the periods 2008-2011 and 2009-2011, respectively, were analyzed statistically. Quarterly effective whole-body doses of the personnel were routinely monitored, using chest badges equipped with Kodak film type 2 in the DNM, and TLD badges in the DDIIR. The dosimetric system of film badges was operated and calibrated at the Central laboratory for radiological protection in Warsaw, whereas the TLD badge system was operated and calibrated at the Laboratory of individual and environmental dosimetry, Institute of Nuclear Physics PAN in Krakow. The method detection limit of both dosimetry methods was $0.1 \mathrm{mSv}$.

Data were grouped according to the occupational category (nuclear medicine and radiology) and the occupational group (medical doctors, technicians, nurses). For the determination of dose constraints, annual doses below the method detection limit were excluded from the analysis: $14(\sim 19 \%)$ for nuclear medicine and $23(\sim 26 \%)$ for radiology. During the analyzed periods, there was no incidence of a dose exceeding the annual dose limit of $20 \mathrm{mSv}$ in either department. For estimation of dose constraint values per occupational group, the dose level below which $75 \%$ of annual doses were respectively included (upper third quartile), as well as the average doses and dominant values achieved by each group during the periods under consideration, was calculated. Based on the above results, the suggested dose constraints for employees of the departments analyzed were proposed.

\section{Results}

Table 1 shows the number of annual doses analyzed for each occupational group in the nuclear medicine and radiology departments for the years 2008-2011 and 2009-2011, respectively. The highest exposure was observed for nuclear medicine nurses and technicians. The average annual doses received for these medical workers were well below the annual dose limit of $20 \mathrm{mSv}$.

The last column shows the proposed dose constraints for employees of the above-mentioned departments. These local dose constraints were selected by taking into account the upper third quartile, below which $75 \%$ of annual doses were respectively included, as well as the average and dominant annual doses achieved by each group during the analyzed periods.

\section{Discussion}

The proposed dose constraints can be used as a usable local level for the current control of exposure to workers in the departments that are presented. The level is adjusted to the local conditions of radiation protection of workplaces and tasks performed by various professional groups. Exceeding the accepted dose constraint by employees should be a signal to intensify individual training or to improve a workplace's level of radiological protection. According to ICRP recommendations, cases of significant excess of dose constraints by employees should be analyzed and investigated (ICRP, 2007). The authors, based on their own experience (PiwowarskaBilska, 2010, 2011, 2013), found it useful, for these purposes, to perform statistical analyses of the number of radioisotope 
procedures conducted in the department and to plot trends over time of individual exposure levels of employees.

It is difficult to assess whether the proposed dose constraints in this paper are similar to those in other countries because of the absence of detailed reports on this subject. One exception is Greece, which introduced fixed dose constraints for the medical sector in 2005, including the different occupational groups and various departments (Kamenopoulou et al., 2001). For all workers in departments of nuclear medicine and radiology in Greece, the dose constraint was set at $2 \mathrm{mSv} /$ year. Surge doses for Greek technicians and medical doctors of nuclear medicine facilities are 2.2 and $1.7 \mathrm{mSv}$ /year, respectively. Readings obtained in Greece, especially for medical doctors in radiology facilities, are much higher than those presented in this article, hence the higher level of dose constraints.

For all exposed workers in Switzerland, if the effective dose determined over the monitoring period is greater than $2 \mathrm{mSv}$, then this must be reported to the supervisory authority (NEAC, 2011). The existing regulations in Ireland prescribe an upper dose of $2 \mathrm{mSv}$ during 16 months for radiation workers and the dose constraint is set at $1 \mathrm{mSv} / \mathrm{year}$ in the design of any new facility.

In the Czech Republic, the system of reference levels (recording, investigation and interventional levels) is established and is required by the current legislation. The dose constraint corresponds to the investigation level, which is set for one month at $1 \mathrm{mSv}$ and for 1 year usually at around $6 \mathrm{mSv}$.

France and Germany have not introduced dose constraints into national regulations but the concept of optimization of radiation protection is clearly included.

In several countries, such as Luxembourg, Norway and Spain, the term dose constraint appears in the legislation but, in practice, is not used as a regulatory tool for the medical sector.

Although the Directive 96/29/Euratom (1996) has already been in force for 17 years, unified EU requirements for the numerical values of dose constraints have not been developed.

The authors, as practitioners, are convinced of their suitability for routine work in the medical sector and they see the need to determine the dose constraints, especially in departments using open ionizing radiation sources, based on a retrospective analysis of the occupational exposure. The dose constraint concept should not only be applied to the effective whole-body doses. There is also a recognized need to determine dose constraints for extremity and eye exposure. This paper is an incentive and an appeal to radiation safety officers to determine local dose constraints on the basis of dose records for the last 3-4 years using simple statistical analysis. It is necessary to periodically reassess or review the estimated numerical values of dose constraints. Due to the large variation in the level of exposure, and depending on the type of medical facility, number of procedures, occupational group and the level of radiological protection, it seems logical to develop a set of dose constraints. Having full information about local exposure levels, the national regulatory authority could be tempted to try to determine the level of dose constraints for various professional groups in various types of medical centers.

\section{Conclusions}

1. The dose constraint is a good and practical tool for radiation protection optimization in the medical departments that use ionizing radiation.

2. The real, local dose constraint for the employees of conventional nuclear medicine facilities must not exceed $2.5 \mathrm{mSv} /$ year, and for the employees of radiology departments, $1 \mathrm{mSv} / \mathrm{year}$.

3. On the basis of sets of local dose constraints, the National Radiation Protection Authority could develop recommended constraints for different types of occupational groups and medical centers.

\section{References}

Croft J., Lefuare C. (2002) Overview of medical occupational exposure issues in the European countries. In: proceedings of the 6th European Alara Workshop EAN, 2002, Madrid.

Euratom (1996) Council Directive 96/29/Euratom, OJ L 159, 29.6., $1-114$

IAEA (1999) Occupational Radiation Protection, IAEA Safety Standards Series No. RS-G-1.1, Vienna.

ICRP Publication 60 (1991) 1990 Recommendations of the International Commission on Radiological Protection. Pergamon Press.

ICRP Publication 103 (2007) Recommendations of the International Commission on Radiological Protection. Pergamon Press.

Kamenopoulou V., Drikos G., Dimitriou P. (2001) Dose constraints to the individual annual doses of exposed workers in the medical sector, Eur. J. Radiol. 37, 204-208.

Martins M.B., Alves J.G., Abrantes J.N., Roda A.R. (2007) Occupational exposure in nuclear medicine in Portugal in the 1999-2003 period, Radiat. Prot. Dosim. 125 (1-4), 130-134.

Nuclear Energy Agency Committee on The Safety of Nuclear Installations (2011) Report NEA/CRPPH/R, http://search.oecd.org/officialdocuments/

Piwowarska-Bilska H., Birkenfeld B., Listewnik M.H., Zorga P. (2010) Long-term monitoring of radiation exposure of employees in the department of nuclear medicine (Szczecin, Poland) in the years 1991-2007, Radiat. Prot. Dosim. 140 (3), 304-307.

Piwowarska-Bilska H., Birkenfeld B., Gwardys A., Supinska A., Listewnik M.H., Elbl B., Cichon-Bankowska K. (2011) Occupational exposure at the Department of Nuclear Medicine as a work environment: A 19-year follow-up, Pol. J. Radiol. 76 (2), 18-21.

Piwowarska-Bilska H., Supinska A., Listewnik M.H., Zorga P., Birkenfeld B. (2013) Radiation doses of employees of nuclear medicine department after implementation of more rigorous radiation protection methods, Radiat. Prot. Dosim., first published online April 24, DOI: 10.1093/rpd/nct107.

Valuckas K.P., Atkocius V., Samerdokiene V. (2007) Occupational exposure of medical radiation workers in Lithuania, 1991-2003, Acta Medica Lituanica 14 (3), 155-159. 